\title{
High-performance inulin and oligofructose prebiotics increase the intestinal absorption of iron in rats with iron deficiency anaemia during the growth phase
}

\author{
Karine de Cássia Freitas ${ }^{1,2}$, Olga Maria Silvério Amancio $^{3}$ and Mauro Batista de Morais ${ }^{2 *}$ \\ ${ }^{1}$ Federal University of Grande Dourados, Dourados, MS, Brazil \\ ${ }^{2}$ Department of Pediatrics, Federal University of São Paulo, Rua Pedro de Toledo, 441, CEP 04039-031, São Paulo, SP, Brazil \\ ${ }^{3}$ Research Laboratory of the Nutrology Discipline, Department of Pediatrics, Federal University of São Paulo, São Paulo, \\ SP, Brazil
}

(Submitted 9 November 2010 - Final revision received 19 September 2011 - Accepted 8 October 2011 - First published online 15 December 2011)

\begin{abstract}
Considering the high frequency of anaemia due to Fe deficiency, it is important to evaluate the effects of prebiotics on the absorption of Fe. The aim of the present study was to evaluate the effects of high-performance (HP) inulin, oligofructose and synergy 1 during recovery from anaemia in rats through the intestinal absorption of $\mathrm{Fe}$, food intake, body growth, caecal $\mathrm{pH}$ and weight of the intestine. Wistar rats $(n$ 47) were fed with rations of AIN93-G with no Fe to induce Fe deficiency anaemia. At $36 \mathrm{~d}$ of life, anaemic rats were divided into four groups: (1) the HP inulin group; (2) the synergy 1 group; and (3) the oligofructose group, all with $100 \mathrm{~g}$ of the respective prebiotic per kg of ration; and (4) a control group, in which the prebiotic was replaced by maize starch. Then, $25 \mathrm{mg}$ of elemental Fe/kg of ration was added to all rations to allow recovery from anaemia. The final values of $\mathrm{Hb}$ in the HP inulin, synergy1, oligofructose and control groups were, respectively: 98 (94-99); 83 (81-92); 100 (90-114); 77 (72-81) g/l, with a statistically significant difference ( $P \leq 0 \cdot 001)$ between the oligofructose and control groups and the HP inulin and control groups. The four groups had an increase in weight and body length and had similar consumption of rations. The intestinal weight and caecal $\mathrm{pH}$ were significantly different between the groups that consumed prebiotics and the control group. HP inulin and oligofructose increased the intestinal absorption of Fe in rats.
\end{abstract}

Key words: Dietary fibre: Inulin: Intestinal absorption: Iron deficiency anaemia: Rats

The interactions between different nutrients in the bioavailability of $\mathrm{Fe}$ and other minerals have been studied in recent decades. Prebiotics are included in the concept of fermentable dietary fibre, which according to physical-chemical characteristics, stand out among the nutrients that can interact with minerals in the intestine ${ }^{(1)}$. Inulin, extracted from chicory, and oligofructose are the prebiotics ${ }^{(2)}$ that are studied most and offer new nutritional perspectives ${ }^{(3)}$. In terms of mineral metabolism, studies in animals and human subjects have shown the benefits of these prebiotics in the absorption of $\mathrm{Ca}$ and $\mathrm{Mg}$ minerals ${ }^{(4-6)}$, but there is little information concerning the effect on the absorption of $\mathrm{Fe}^{(7,8)}$.

In this context, studies that show a synergistic effect for the absorption of $\mathrm{Ca}$ and $\mathrm{Mg}$ must also be considered when fibres with different chain sizes are offered together ${ }^{(4,9)}$. Some authors report that the enhancement of $\mathrm{Ca}$ absorption with products made from both types of dietary fibre, such as synergy1 (which is made up of 50\% high-performance (HP) inulin and $50 \%$ oligofructose), could result from fermentation that extends along the entire large intestine ${ }^{(4)}$. To our knowledge, the effect of synergyl on the absorption of Fe has not yet been compared to other types of fibres. Current studies show beneficial results on the absorption of $\mathrm{Fe}$ associated with more fermentable dietary fibre ${ }^{(10,11)}$.

There is also clinical relevance in evaluating the effect of functional fibres in Fe absorption concerning the introduction of fibre-rich complementary food in infant nutrition aiming to prevent the beginning of chronic constipation ${ }^{(12,13)}$. On the other hand, early introduction of foods rich in dietary fibre may have negative effects on growth and on the bioavailability of minerals, including $\mathrm{Fe}$. In this stage of life, between 6 months and 24 months, Fe deficiency anaemia occurs at a high prevalence ${ }^{(14,15)}$ and may cause several negative repercussions in infant health ${ }^{(15,16)}$. Optimising the bioavailability of Fe present in food ${ }^{(17,18)}$ is one of the ways to prevent $\mathrm{Fe}$ deficiencies. There is still no recommendation regarding the

Abbreviation: HP, high performance.

*Corresponding author: Dr M. B. de Morais, email mbmorais@osite.com.br 
consumption of fibre in the first year of life, probably because of concerns that fibre may have negative effects on growth and on the bioavailability of minerals. Thus, the American Academy of Pediatrics, the American Health Foundation and the Institute of Medicine, which are responsible for the development of Dietary Reference Intake, exclude the first year of life in their recommendations ${ }^{(19,20)}$. The lack of guidelines regarding fibre in this age group shows the necessity for evaluating whether the consumption of prebiotics interferes with the bioavailability of Fe.

Therefore, the present experimental study evaluates the effect of HP inulin, oligofructose and synergy 1 prebiotics on the intestinal absorption of Fe, food intake, body growth, colon and caecum weight, caecal $\mathrm{pH}$ and weight of the faeces of rats with Fe deficiency anaemia compared to anaemic rats fed with rations without dietary fibre.

\section{Experimental methods}

\section{Animals and diets}

A total of forty-eight male Wistar rats, aged $21 \mathrm{~d}$ at the start of the experiment, were used in the present study. Throughout the study period, they received rations and deionised water through the MilliQ Plus system (Millipore Corporation) ad libitum. All rats were kept in individual metabolic cages made of acrylic and stainless steel (Nalgene-Metabolic Cages 650-0100) on a cycle of $12 \mathrm{~h}$ of light and at a temperature of $23 \pm 1^{\circ} \mathrm{C}$. The use of cages preventing coprophagia and contamination with $\mathrm{Fe}$ also allowed the apparent absorption to be evaluated.

Animals were fed with rations recommended by the American Institute of Nutrition (AIN93-G) ${ }^{(21)}$, containing the nutrients needed for proper growth of rats. To induce Fe deficiency anaemia, Fe was not added to the rations during the first 2 weeks of the study. In the 5 th week of life
(36 d old), the rats were divided into four groups according to weight, body length and the rate of $\mathrm{Hb}$ and haematocrit, with the aim of forming similar groups based on these parameters. Thus, four groups were comprised of twelve animals that started to receive one of the following rations, with the respective added prebiotic (Orafti, Active Food Ingredients $^{\circledR}$ ): (1) HP inulin group - regular rations with $103 \cdot 1 \mathrm{~g}$ of HP inulin ( $100 \mathrm{~g}$ of dietary fibre); (2) synergy1 group regular rations with $112 \cdot 36 \mathrm{~g}$ of synergy 1 ( $100 \mathrm{~g}$ of dietary fibre); (3) oligofructose group - regular rations with $108.7 \mathrm{~g}$ of oligofructose (100 g of dietary fibre); (4) control group regular rations without dietary fibre, which was replaced by $100 \mathrm{~g}$ of maize starch, as suggested in the literature ${ }^{(22)}$. The amount of HP inulin, synergy1 and oligofructose was subtracted from the total amount of maize starch in the ration.

Initially, a portion of the rations that was equivalent to the sum of the quantity to be ingested by the four groups during the experimental period was prepared. It was made up of the ingredients common to all groups of the study, in its smaller quantity, and to this volume elemental $\mathrm{Fe}(25 \mathrm{mg} / \mathrm{kg}$ of the ration) in the form of hydrated ferric citrate $\left(\right.$ Merck $^{\circledR}$ ) was added. This procedure aimed to avoid oscillations in the content of Fe offered to each of the four groups in the study. The content of Fe was determined in the rations, with or without added Fe, measured in three samples through an atomic absorption spectrometer, model Perkin-Elmer $5100 \mathrm{PC}^{(23)}$. According to the laboratory dosage, the average quantities of elemental $\mathrm{Fe}$ in the ration, with or without added Fe, were: 36.0 and $10.0 \mathrm{mg} / \mathrm{kg}$ per ration, respectively. The total volume of the ration was divided into four equal parts and the necessary adjustments of the ingredients were made to form the four groups of the study. The composition of each diet is described in Table 1.

Each week, after beginning the supply of the experimental diets, the weight and the length of each animal were

Table 1. AIN93-G ration composition, indicated for rats in the growth phase, changed by the replacement of $50 \mathrm{~g}$ of cellulose and $50 \mathrm{~g}$ of starch for $100 \mathrm{~g}$ of high-performance (HP) inulin, synergy 1 , oligofructose and maize starch (control diet) and a reduction of the iron content that was added $(25 \mathrm{mg} / \mathrm{kg}$ ration)

\begin{tabular}{|c|c|c|c|c|}
\hline Ingredients (g/kg) & HP inulin* & Synergy1† & Oligofructose & Control \\
\hline HP inulin & $103 \cdot 1$ & 0.00 & 0.00 & 0.00 \\
\hline Synergy1 & 0.00 & $112 \cdot 36$ & 0.00 & 0.00 \\
\hline Oligofructose & 0.00 & 0.00 & $108 \cdot 7$ & 0.00 \\
\hline Maize starch & $476 \cdot 39$ & $475 \cdot 13$ & $475 \cdot 79$ & 579.49 \\
\hline Casein & $200 \cdot 00$ & $200 \cdot 00$ & $200 \cdot 00$ & $200 \cdot 00$ \\
\hline Sucrose & $100 \cdot 00$ & 92.00 & 95.00 & $100 \cdot 00$ \\
\hline Soyabean oil & $70 \cdot 00$ & $70 \cdot 00$ & $70 \cdot 00$ & $70 \cdot 00$ \\
\hline L-Cystine & 3.00 & 3.00 & 3.00 & 3.00 \\
\hline Choline bitartrate & 2.50 & 2.50 & $2 \cdot 50$ & $2 \cdot 50$ \\
\hline T-butylhydroquinone & 0.014 & 0.014 & 0.014 & 0.014 \\
\hline Vitamin mix§ & $10 \cdot 00$ & $10 \cdot 00$ & $10 \cdot 00$ & $10 \cdot 00$ \\
\hline Mineral mix without Fe\|l & $35 \cdot 00$ & 35.00 & 35.00 & 35.00 \\
\hline Ferric citrate $(19 \%)$ & 0.129 & 0.128 & 0.129 & 0.132 \\
\hline
\end{tabular}

* Composition of macronutrients in $100 \mathrm{~g}$ of the product inulin HP: carbohydrates, $0 \mathrm{~g}$; protein, $0 \mathrm{~g}$; total fat, $0 \mathrm{~g}$; dietary fibre, $97 \mathrm{~g}$.

† Synergy1: carbohydrates, $8 \mathrm{~g}$; protein, $0 \mathrm{~g}$; total fat, $0 \mathrm{~g}$; dietary fibre, $89 \mathrm{~g}$.

$\ddagger$ Oligofructose: carbohydrates, $5 \mathrm{~g}$; protein, $0 \mathrm{~g}$; total fat, $0 \mathrm{~g}$; dietary fibre, $92 \mathrm{~g}$.

$\S\left(\right.$ Roche $\left.{ }^{\circledR}\right)$ : Composition in mg: nicotinic acid, 30; pantothenate, 15; pyridoxine, 6; thiamine, 5; riboflavin, 6; folic acid, 2; composition in $\mu$ g: vitamin K, 750; D-biotin, 200; vitamin $B_{12}, 25$; composition in IU: vitamin A, 4000; vitamin $D_{3}, 1000$; vitamin $E, 75$.

$\|\left(\right.$ Roche $\left.^{\circledR}\right)$ : Composition in mg - essential minerals - Ca, 5000; P, 1561; K, 3600; S, 300; Na, 1019; Cl, 1571; Mg, 507; Zn, 30; Mn, 10; Cu, 6; I, 0.2; Mo, 0.15; Se, 0.15 - potentially beneficial minerals - Si, 5; Cr, 1; F, 1; Ni, 0.5; B, 0.5; Li, 0.1; V 0.1-without Fe. 
measured. A calculation of the feed efficiency coefficient was conducted on each diet week through the following formula: weight gain $(\mathrm{g})$ /ration consumption $(\mathrm{g})$ in the same period.

\section{Measurement of anaemia-related biochemical variables}

The animal was anaesthetised by inhalation of isoflurane and a sample of blood was taken from the tail for determination of $\mathrm{Hb}$ and haematocrit. During this period, food intake was measured daily.

Then, $10 \mathrm{~d}$ after the start of the supply of experimental rations, $0.1 \mathrm{~g}$ of carmine-pink colorant was added to the ration of each animal and, during three consecutive days, faeces were collected the moment a change in colour (to a reddish colour) was observed. After $72 \mathrm{~h}$ of the addition of rose-carmine into the rations, Evans blue colorant (Inlab, soluble in water) was added to the ration. The collection was interrupted at the point when excretion of blue-coloured faeces began.

The faeces collected during this $3 \mathrm{~d}$ period were properly identified and stored in a freezer $\left(-20^{\circ} \mathrm{C}\right)$. After the 3 rd day of collection, the humid weight of the faeces was obtained on an electronic analytical balance (Metler Toledo - model AB204) with a sensitivity of $0.0001 \mathrm{~g}$. Then, the faeces were dried in an oven at $105^{\circ} \mathrm{C}$ and, after $22 \mathrm{~h}$, the faeces were weighed at $30 \mathrm{~min}$ intervals, until a constant weight was obtained. The humidity of the faeces was calculated using the formula: (fresh faecal weight - dry faecal weight/fresh faecal weight) $\times 100$.

Following this, $500 \mathrm{mg}$ of dried faeces from each animal were weighed and divided into two samples of $250 \mathrm{mg}$ (duplicates) that were submitted to net digestion (using NO and perchloric acid). The Fe analysis was performed in an atomic absorption spectrometer. The amount of Fe intake in the same period of time was also calculated. The percentage of Fe absorbed was calculated using the following formula: (ingested $\mathrm{Fe}$ quantity - excreted $\mathrm{Fe}$ quantity/ingested $\mathrm{Fe}$ quantity) $\times 100$.
On the 21st day of the experimental diets, the animals were killed by inhalation of isoflurane. Median incisions in the abdominal wall and in the peritoneum were made and the caecum was isolated by cutting between the ileocaecal valve and the beginning of the proximal colon. After removing the caecum, the colon was separated into two portions ${ }^{(24)}$, with the first considered to be the proximal colon (located between the caecum and the median portion of the larger colonic curvature) and the second as the distal colon (located between the median portion of the larger colonic curvature and the peritoneal reflection of the rectum) ${ }^{(25)}$. All of the intestinal portions were weighed fresh on filter paper on an electronic analytical balance (Metler Toledo - model AB204), with a sensitivity of $0.0001 \mathrm{~g}$, after excision of the mesentery, and were washed with physiological serum for removal of the contents in the lumen. At this point, the $\mathrm{pH}$ of the caecal contents was also evaluated. The animals were killed between 06.00 and 10.00 hours, the period in which the intestinal fermentation is more active ${ }^{(9,26)}$. The caecal content was placed in a beaker immediately after extraction of the organ and the $\mathrm{pH}$ was measured using a pH-meter (Micronal - pH-meter B374). Finally, the liver was excised. The liver was weighed fresh, submitted to drying in an oven for $22 \mathrm{~h}$ at $120^{\circ} \mathrm{C}$ and was weighed three more times consecutively until the constant dry weight was obtained.

$\mathrm{Hb}$ levels were determined by the method of cyanomethahaemoglobin and microhaematocrit by the Wintrobe $\operatorname{method}^{(27)}$. The determination of hepatic Fe was also performed after liquid digestion of the dry tissue through atomic absorption spectrophotometry, similar to the method mentioned earlier for faeces.

\section{Statistical analysis}

The results are expressed as mean values and standard deviations when the numerical variables had a normal distribution. An ANOVA was used for comparisons between groups. When the analysis showed a statistically significant difference, it was

Table 2. Weekly and total intake of rations, weekly body weight and weekly and total feed efficiency coefficients (CEA) in animals of the high-performance (HP) inulin, synergy 1 , oligofructose and control groups

(Mean values and standard deviations)

\begin{tabular}{|c|c|c|c|c|c|c|c|c|c|c|}
\hline \multirow[b]{2}{*}{ Variables } & \multirow[b]{2}{*}{ Period } & \multicolumn{2}{|c|}{ HP inulin ( $n$ 12) } & \multicolumn{2}{|c|}{ Synergy1 ( $n$ 12) } & \multicolumn{2}{|c|}{$\begin{array}{l}\text { Oligofructose } \\
\quad(n 11)\end{array}$} & \multicolumn{2}{|c|}{ Control (n 12) } & \multirow[b]{2}{*}{$P$} \\
\hline & & Mean & SD & Mean & SD & Mean & SD & Mean & SD & \\
\hline \multirow{4}{*}{ Food intake (g) } & Week 1 & 97.98 & 11.32 & 96.73 & $11 \cdot 20$ & 92.33 & 8.49 & 98.65 & 14.58 & 0.575 \\
\hline & Week 2 & 111.40 & 12.95 & 107.99 & $10 \cdot 89$ & $107 \cdot 36$ & 11.00 & $112 \cdot 21$ & 14.75 & 0.729 \\
\hline & Week 3 & 115.50 & 9.39 & $112 \cdot 10$ & 13.47 & $106 \cdot 14$ & 14.35 & 113.62 & $16 \cdot 72$ & 0.409 \\
\hline & Total & 324.88 & $29 \cdot 14$ & $316 \cdot 82$ & 32.56 & 305.83 & $27 \cdot 52$ & 324.53 & 43.84 & 0.509 \\
\hline \multirow[t]{3}{*}{ Body weight (g) } & Week 1 & 147.41 & $12 \cdot 47$ & 143.36 & 11.35 & 139.77 & 16.44 & $146 \cdot 76$ & 18.34 & 0.594 \\
\hline & Week 2 & $186 \cdot 13$ & 19.37 & 182.68 & $14 \cdot 83$ & $176 \cdot 75$ & $17 \cdot 34$ & $189 \cdot 47$ & 22.09 & 0.415 \\
\hline & Week 3 & 221.58 & 24.42 & $215 \cdot 36$ & $19 \cdot 36$ & 208.06 & 24.90 & 225.79 & 27.44 & 0.333 \\
\hline \multirow[t]{3}{*}{ Body length $(\mathrm{cm})$} & Week 1 & 31.83 & 1.51 & 31.67 & 1.09 & 31.46 & 1.49 & 31.96 & 1.22 & 0.821 \\
\hline & Week 2 & $34 \cdot 21$ & 1.80 & 34.58 & 1.33 & 34.09 & $1 \cdot 79$ & $34 \cdot 21$ & $1 \cdot 25$ & 0.880 \\
\hline & Week 3 & 36.58 & 1.58 & $36 \cdot 71$ & 1.62 & $36 \cdot 14$ & 1.96 & 36.54 & 1.57 & 0.865 \\
\hline \multirow[t]{4}{*}{ CEA } & Week 1 & 0.31 & 0.05 & 0.30 & 0.03 & 0.26 & 0.07 & 0.31 & $0 \cdot 10$ & 0.229 \\
\hline & Week 2 & 0.35 & 0.06 & 0.36 & 0.03 & 0.35 & 0.06 & 0.38 & 0.06 & 0.318 \\
\hline & Week 3 & 0.31 & 0.04 & 0.29 & 0.05 & 0.29 & 0.09 & 0.32 & 0.05 & 0.602 \\
\hline & Total & 0.32 & 0.04 & 0.32 & 0.02 & 0.30 & 0.06 & 0.34 & 0.04 & 0.180 \\
\hline
\end{tabular}


complemented with Tukey's test, which was calculated with the use of the Jandel Sigma-Stat program (Systat Software Inc.). Statistical significance was defined as $P<0.05$.

The Kruskal-Wallis test was used for the numerical variables that did not have a normal distribution. When there was a statistically significant difference, the analysis was complemented with the Dunn test.

\section{Ethical considerations}

The study protocol was approved by the Research Ethics Committee of the Federal University of Sao Paulo and was conducted in compliance with the International Guiding Principles for Biomedical Research Involving Animals (Council for International Organizations of Medical Sciences) Geneva, 1985.

\section{Results \\ Growth and food intake}

At the beginning of the dietary treatment, the weights of the rats in the HP inulin, synergy1, oligofructose and control groups were, respectively: $117 \cdot 23$ (SD 9.18), 114.66 (SD 9.08), 115.93 (SD 12.39) and 115.98 (SD 10.61) g $(P=0.946)$. The trend for body length (body + tail) was similar: 29.13 (SD 0.96), 29.04 (SD 1.23), 28.73 (SD 0.96) and 29.00 (SD 0.95) $\mathrm{cm}$ ( $P=0.816$ ). The $\mathrm{Hb}$ values obtained from the HP inulin, synergy1, oligofructose and control groups were, respectively: $56 \cdot 5(55 \cdot 3-58 \cdot 2), 57 \cdot 1(54 \cdot 5-60 \cdot 0), 58 \cdot 0(52 \cdot 6-59 \cdot 0)$ and $56 \cdot 1$ $(53.6-59.3) \mathrm{g} / 1 \quad(P=0.925)$. The haematocrit values, in the same order, were: $17 \cdot 50(16 \cdot 75-18.00), 17 \cdot 00(16.50-19 \cdot 00)$, $18.00(17 \cdot 00-19 \cdot 00)$ and $18.00(17 \cdot 00-18 \cdot 50) \%(P=0.857)$. Considering weight, length, $\mathrm{Hb}$ and haematocrit, the four groups were similar before the experimental diets were started.

After the experimental rations were offered, one animal in the oligofructose group had a low food intake, low weight gain, diarrhoea, and a behaviour quite different from the other animals. As the days passed, these symptoms continued, and the animal was removed from the study. Kept on standard rations, these symptoms continued, and the animal was killed.

Table 2 shows the weekly intake for each group, the total intake over a period of $21 \mathrm{~d}$, the weekly weight and body length, and the feed efficiency coefficient generated in each period. There was no statistically significant difference between the groups in any of the weeks evaluated.

The total volume of deionised water intake during the period of $21 \mathrm{~d}$ of dietary treatment for the HP inulin, synergy1, oligofructose and control groups was, respectively: 677.33 (SD 22.19), 645.00 (SD 16.09), 672.33 (SD 17.47) and $489.67(\mathrm{SD} 5.51) \mathrm{ml}(P<0.001)$, with a statistically significant difference between the HP inulin and control groups $(P<0 \cdot 001)$, the synergy1 and control groups $(P<0 \cdot 001)$, and the oligofructose and control groups $(P<0 \cdot 001)$. No statistically significant difference was observed between the groups receiving the prebiotic $(P>0.05)$ according to the multiplecomparisons Tukey's test.

\section{Anaemia-related values}

Fig. 1(a) shows the changes in the weekly values of $\mathrm{Hb}(\mathrm{g} / \mathrm{l})$ presented by the four groups after initiation of the dietary treatment. The synergy 1 and control group values progressed without statistically significant differences between them, while the HP inulin and oligofructose groups presented a higher elevation of the $\mathrm{Hb}$ and haematocrit with statistically significant differences in relation to the control group $(P<0.05)$. The difference between synergy1 and HP inulin or oligofructose was not significant at any of the time points.

The weekly values of haematocrit confirmed the evolution of the $\mathrm{Hb}$ (Fig. 1(b)). During the 3 weeks of evaluation, the synergy 1 and control group values progressed without statistically significant differences between them, while the HP inulin and oligofructose groups presented a higher elevation of haematocrit, with a statistically significant difference in relation to the control group $(P<0 \cdot 05)$.
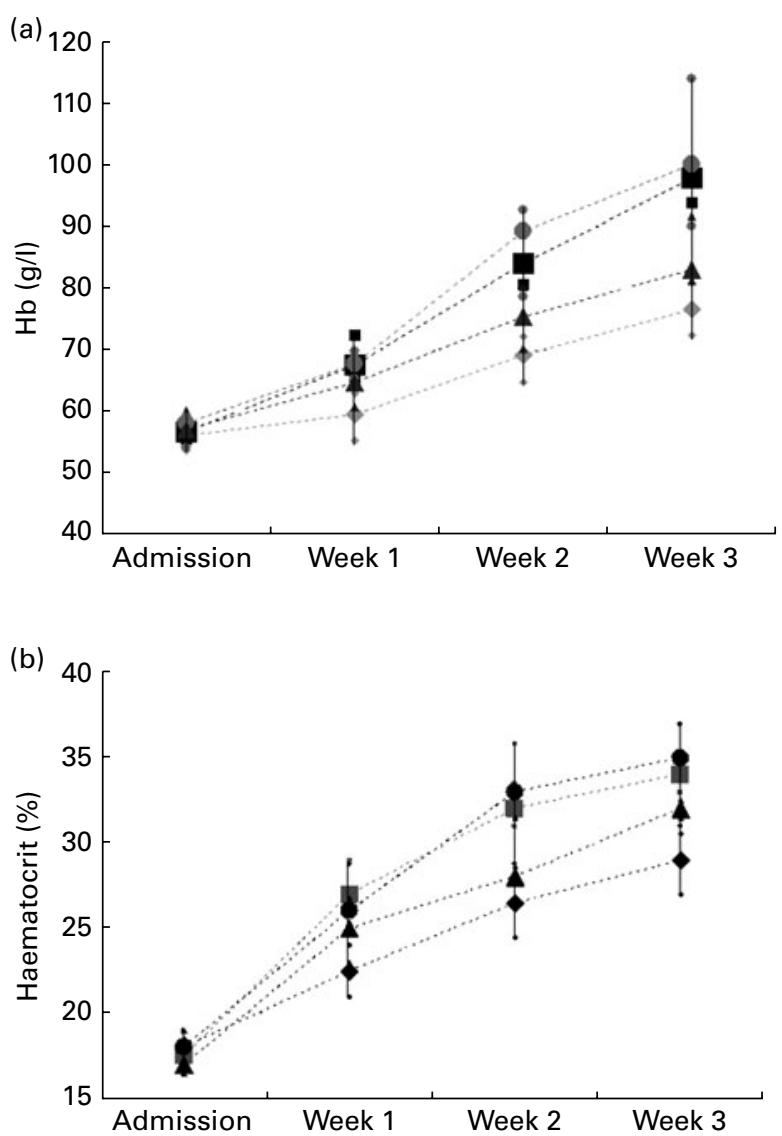

Fig. 1. Median and percentiles (25th-75th) of the values of (a) $\mathrm{Hb}(\mathrm{g} / \mathrm{l})$ and (b) haematocrit (\%) in the high-performance (HP) inulin ( $\square, \square)$, synergy1 $(\boldsymbol{\Delta}, \boldsymbol{\Delta})$, oligofructose $(\mathrm{O}, \boldsymbol{\bullet})$ and control $(\diamond, \diamond)$ groups, before treatment and at each week of the experimental rations. There were no significant differences ( $\mathrm{a}, P<0.925$; $\mathrm{b}, P=0.857$ ). Week 1: HP inulin $>$ control; oligofructose $>$ control; synergy $1 \simeq$ control; HP inulin $\simeq$ oligofructose; HP inulin $\simeq$ synergy 1 ; oligofructose $\simeq$ synergy 1 ((a) $P=0.010$; (b) $P=0.002$ ). Week 2 : $\mathrm{HP}$ inulin $>$ control; oligofructose $>$ control; synergy $1 \simeq$ control; HP inulin $\simeq$ oligofructose; $\mathrm{HP}$ inulin $\simeq$ synergy1; oligofructose $\simeq$ synergy1 $(P=0.001)$. Week 3: HP inulin > control; oligofructose > control; synergy $1 \simeq$ control; HP inulin $\simeq$ oligofructose; $\quad$ HP $\quad$ inulin $\simeq$ synergy $1 ; \quad$ oligofructose $\simeq$ synergy 1 $(P \leq 0.001)$. 


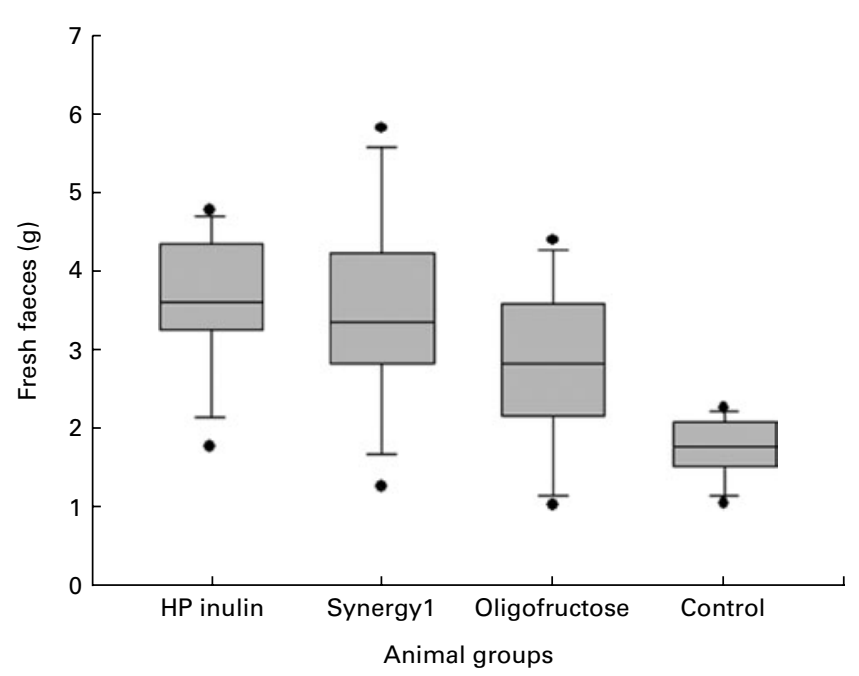

Fig. 2. Median and 25th and 75th percentiles of the fresh faeces (weight) collected over a period of $72 \mathrm{~h}$ during the experimental rations. Highperformance $(\mathrm{HP})$ inulin $>$ control; synergy $1>$ control; oligofructose $\simeq$ control; HP inulin $\simeq$ oligofructose; $\mathrm{HP}$ inulin $\simeq$ synergy 1 ; synergy $1 \simeq$ oligofructose $(P \leq 0.001)$.

The apparent absorption of Fe was evaluated over $72 \mathrm{~h}$ and was considered as the difference between the total intake and the total amount excreted in the faeces. The apparent absorption showed a statistically significant difference between the HP inulin and control groups and between the oligofructose and control groups. This was not observed between the synergy 1 and control groups $(P>0.05)$. In absolute terms, the averages presented by the HP inulin, synergy1, oligofructose and control groups were, respectively: 68.21 (SD 17.69), 56.71 (sD 22.74), 72.02 (sD 15.31) and 46.83 (SD 19.14) \% ( $P=0 \cdot 010)$.

The fresh weight of the liver was 12.53 (SD 2.02) $\mathrm{g}$ in the HP inulin group, 12.67 (SD 1.73) $\mathrm{g}$ in the synergy1 group, 12.60 (SD $2.06) \mathrm{g}$ in the oligofructose group and 12.57 (SD 2.84) $\mathrm{g}$ in the control group $(P=0.999)$. The content of hepatic Fe determined in the dry tissue was 224.97 (SD 79.33) $\mu \mathrm{g} / \mathrm{g}$ in the HP inulin group, $215 \cdot 20$ (SD 70.56$) \mu \mathrm{g} / \mathrm{g}$ in the synergy1 group, $212 \cdot 73(\mathrm{SD} 49 \cdot 38) \mu \mathrm{g} / \mathrm{g}$ in the oligofructose group and 180.67 (SD $77 \cdot 22) \mu \mathrm{g} / \mathrm{g}$ in the control group $(P=0 \cdot 454)$.

\section{Weight of faeces}

Fig. 2 shows the differences in the weight of the fresh faeces collected over $72 \mathrm{~h}$ from the 10th day that the experimental rations were offered to the four groups. These statistical differences remained after the faeces were dried in the oven. The averages of the dry weights of the faeces were: 1.68 (SD 0.55), 1.64 (sD 0.33), 1.32 (sD 0.41) and 1.11 (sD 0.24) g for the HP inulin, synergy, oligofructose and control groups, respectively $(P=0.003)$. The humidity of the faeces was $54.94(\mathrm{sD} 10 \cdot 28) \%$ in the HP inulin group, $50 \cdot 84$ (SD 12.38) \% in the synergy1 group, $49 \cdot 61$ (SD 14.35) \% in the oligofructose group and 37.46 (SD 6.40)\% in the control group $(P=0.003)$. Significant differences between the HP inulin group and the control group and between the synergy 1 group and the control group were observed.

\section{Caecal characteristics}

Table 3 shows the weights of the different intestinal areas extracted after the animals were killed and the statistical differences obtained in each case. Fig. 3 shows the macroscopic aspect of the caecum of the different groups. The average values of the caecum $\mathrm{pH}$ in the HP inulin, synergy1, oligofructose and control groups were, respectively: $5 \cdot 05$ (SD 0.42), 5.09 (SD 0.29), 4.82 (SD 0.19) and 6.61 (SD 0.22). A statistically significant difference was observed between the groups receiving prebiotics and the control group $(P \leq 0 \cdot 001)$, while no significant difference was observed in the comparison between the groups consuming prebiotics $(P>0.05)$.

\section{Discussion}

The present study shows that inulin and oligofructose increase Fe biodisponibility while synergy 1 did not differ from the control group. All the experimental groups (except the control group) presented an increase in the caecum weight and a decrease in the luminal $\mathrm{pH}$. On the other hand, growth was similar in all groups.

There is evidence in the literature that interference with food intake can have negative effects on the growth of

Table 3. Weights (g) of: the caecum with the caecal content, the caecal wall, the proximal colon, the distal colon and the total colon in animals of the high-performance (HP) inulin, synergy1, oligofructose and control groups

(Median values with their 25 th and 75 th percentiles)*

\begin{tabular}{|c|c|c|c|c|c|c|c|c|c|}
\hline \multirow[b]{2}{*}{ Variables } & \multicolumn{2}{|c|}{ HP inulin ( $n$ 12) } & \multicolumn{2}{|c|}{ Synergy1 ( $n$ 12) } & \multicolumn{2}{|c|}{ Oligofructose $(n 11)$} & \multicolumn{2}{|c|}{ Control $(n 12)$} & \multirow[b]{2}{*}{$P$} \\
\hline & Median & $\begin{array}{l}\text { 25th-75th } \\
\text { percentile }\end{array}$ & Median & $\begin{array}{l}\text { 25th-75th } \\
\text { percentile }\end{array}$ & Median & $\begin{array}{l}\text { 25th-75th } \\
\text { percentile }\end{array}$ & Median & $\begin{array}{l}\text { 25th-75th } \\
\text { percentile }\end{array}$ & \\
\hline Caecum with content $(\mathrm{g})$ & $7.65^{\mathrm{a}}$ & $6.48-9.52$ & $7.73^{\mathrm{a}}$ & $7.05-8.41$ & $8 \cdot 31^{a}$ & $6.68-9.65$ & $2 \cdot 15^{\mathrm{b}}$ & $1.94-2.61$ & $\leq 0.001$ \\
\hline Caecal content (g) & $6 \cdot 03^{a}$ & $4.95-7.73$ & $6 \cdot 11^{a}$ & $5.46-6.49$ & $5 \cdot 94^{\mathrm{a}}$ & $4.96-7.90$ & $1.63^{\mathrm{b}}$ & $1.30-1.97$ & $\leq 0.001$ \\
\hline Caecal wall $(\mathrm{q})$ & $1.72^{\mathrm{a}}$ & $1.52-2.00$ & $1.67^{\mathrm{a}}$ & $1.59-1.83$ & $1.89^{\mathrm{a}}$ & $1.73-1.96$ & $0.59^{b}$ & $0.48-0.65$ & $\leq 0.001$ \\
\hline Proximal colon (g) & $0.68^{\mathrm{b}}$ & $0.66-0.82$ & $0.71^{b}$ & $0.59-0.87$ & $0.90^{\mathrm{a}}$ & $0.81-0.97$ & $0.58^{b}$ & $0.53-0.64$ & $\leq 0.001$ \\
\hline Distal colon $(\mathrm{g})$ & $0.25^{\mathrm{a}}$ & $0.22-0.30$ & $0.23^{a}$ & $0.21-0.29$ & $0 \cdot 19^{b}$ & $0.15-0.23$ & $0 \cdot 16^{\mathrm{b}}$ & $0.15-0.17$ & $\leq 0.001$ \\
\hline $\begin{array}{l}\text { Total colon (g) } \\
\text { (proximal + distal) }\end{array}$ & $1.01^{a}$ & $0.91-1.07$ & $0.93^{\mathrm{a}}$ & $0.81-1.15$ & $1 \cdot 10^{\mathrm{a}}$ & $0.95-1.21$ & $0.74^{\mathrm{b}}$ & $0.69-0.79$ & $\leq 0.001$ \\
\hline
\end{tabular}

${ }^{a, b}$ Median values within a row with unlike superscript letters were significantly different in comparisons between groups $(P<0.05)$.

${ }^{*}$ Kruskal-Wallis test. 
(a)

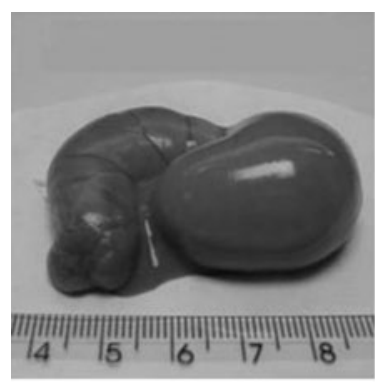

(c)

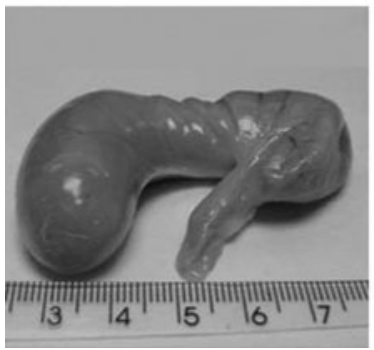

(b)

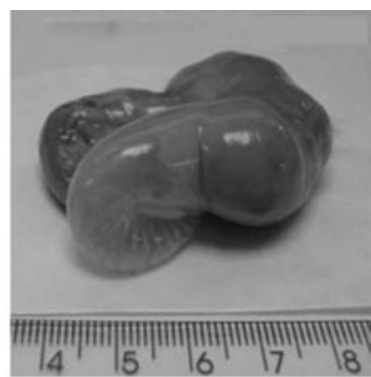

(d)

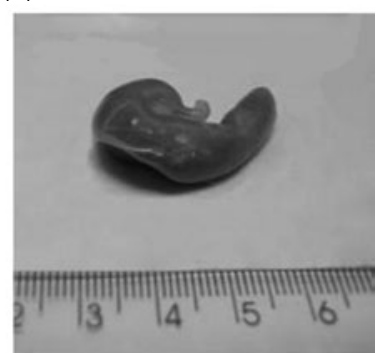

Fig. 3. Caecum immediately after extraction from each group. (a) High performance inulin group; (b) Synergy1 group; (c) oligofructose group; (d) control group.

infants $^{(28)}$ and in the absorption of minerals ${ }^{(29)}$, which probably justifies why there is no fibre recommendation for children up to 1 year of age ${ }^{(19,20)}$. However, recent studies mention the benefits of dietary fibre ${ }^{(11,30)}$ and prebiotics for the absorption of $\mathrm{Ca}$ and $\mathrm{Mg}$ in animals ${ }^{(9,10,31)}$ and humans ${ }^{(5,6)}$. Few studies have been conducted on animals to evaluate the absorption of $\mathrm{Fe}$, which showed either a benefit or a lack of influence ${ }^{(12,32-35)}$. In our study, the progression in the values of $\mathrm{Hb}$ and haematocrit during the 3 weeks of prebiotic intake showed a higher $\mathrm{Hb}$ regeneration in the $\mathrm{HP}$ inulin and oligofructose groups, in accordance with the literature ${ }^{(12,32-34)}$. In addition to the previous studies ${ }^{(32-34)}$, the present study also evaluated the effect of synergy 1 on $\mathrm{Fe}$ absorption. Although the synergy1 group had a higher and faster regeneration of haemoglobinic mass in relation to the control group, it was not significantly different in any of the three evaluations performed.

To sensitise the model used in our study, we made the haemoglobinic regeneration slower, and the amount of Fe used in this experiment was less than that recommended by the American Institute of Nutrition (AIN93-G: $35 \mathrm{mg} / \mathrm{kg}$ of ration) ${ }^{(21)}$. Thus, $25 \mathrm{mg}$ of $\mathrm{Fe} / \mathrm{kg}$ of ration was added. Experiments that were carried out in our laboratory previously showed that this model is efficient to evaluate the effects of dietary fibre ${ }^{(11,35,36)}$ on the absorption of Fe.

Progression of the values of $\mathrm{Hb}$ and haematocrit during the 3 weeks of prebiotic intake showed a higher $\mathrm{Hb}$ regeneration in the HP inulin and oligofructose groups, in accordance with the literature ${ }^{(7,32-34)}$. However, although the synergy1 group had a higher and faster regeneration of haemoglobinic mass in relation to the control group, it was not significantly different in any of the three evaluations performed.
Studies have reported that synergy1 benefits the absorption of $\mathrm{Ca}$ and $\mathrm{Mg}$ in the upper level compared to the prebiotics offered separately, with a synergistic effect apparently coming from the combination of prebiotics ${ }^{(4)}$. This effect was not found regarding the absorption of Fe when compared to HP inulin and oligofructose, indicating that the apparent absorption of $\mathrm{Fe}$ confirmed the $\mathrm{Hb}$ and haematocrit results.

In the literature, there is a strong interest in defining how some types of dietary fibre could benefit the absorption of minerals ${ }^{(37,38)}$. Regarding Fe, a partial explanation comes from recent studies on the Fe absorption capacity of the large intestine in animals. The large intestine is the location of fermentation of prebiotics, which increases the expression of genes for the absorption of Fe, although these receptors exist in lower concentrations than in the duodenum ${ }^{(37-39)}$. In $2007^{(37)}$, a study on pigs showed that colonic absorption in these animals was equivalent to $14 \%$ of the duodenal absorption.

Parallel to this capability, the increase in the superficial area of absorption is a consequence of the trophic effect generated by non-digestible oligosaccharides on the caecum and colon $^{(26,40)}$, which is related to the production of SCFA ${ }^{(41)}$. The trophic effect produced by the prebiotics studied here may be indicated by the larger weight of the caecal wall and the proximal and distal colon in relation to the control group.

Also, the production of SCFA decreases the value of caecal $\mathrm{pH}$, generating benefits on the intestinal absorption of minerals and allowing higher solubility of ions, including $\mathrm{Fe}^{(40)}$ In this study, the $\mathrm{pH}$ measured in the caecum was lower among the groups receiving the prebiotics than the control group. It is also known that SCFA can form soluble complexes with $\mathrm{Fe}^{(42)}$, facilitating the entry of $\mathrm{Fe}$ into intestinal cells. Another study observed that Fe deficiency in young women in South India was associated with low levels of lactobacilli in the faeces ${ }^{(43)}$, suggesting that the intestinal bacterial flora may facilitate absorption of Fe from the caecum and proximal colon. It was observed that inulin enhanced the abundance of beneficial bifidobacteria and lactobacilli in the microbiota adherent to intestinal mucus in various gut segments of pigs. Therefore, the ability of dietary inulin to alter intestinal bacterial populations may partially account for the Fe bioavailability-promoting effect ${ }^{(44,45)}$.

However, it should be emphasised that the effects of fibre on absorption are not restricted to the colon. The apparent absorption of minerals in pigs receiving resistant starch or digestible starch had higher absorption of these substances, including $\mathrm{Fe}$ in the group receiving resistant starch, although the digested material was collected in the terminal ileum. The authors relate the increase in the transition time generated by the resistant starch to higher absorption due to the increased time in which the food was in contact with the intestinal wall ${ }^{(46)}$. An increase in the surface generated by the fibre and in the products of fermentation can also occur in the small intestine through a stimulus via systemic mediation. The possible causes of this mediation are the autonomic nervous system, the peptide hormone YY, enteroglucagon, glucagonlike peptide, gastrin ${ }^{(41,47)}$ and the increased number of $\mathrm{Fe}$ receptors stimulated by the intake of prebiotics ${ }^{(39)}$. 
It is interesting to observe the effect of synergy1 on the absorption of Fe. Although there is more regeneration of $\mathrm{Hb}$ in this group in comparison to the control group, this difference is not statistically significant. In turn, the effect on the caecal $\mathrm{pH}$ and the weight of the intestinal wall in this group was similar to the other groups consuming prebiotics.

In 2007, Tako et al. ${ }^{(39)}$ offered synergy1 as a source of inulin and confirmed the increase of such receptors when evaluating the change of receptors for $\mathrm{Fe}$ in different places of the intestines of pigs that consumed prebiotics. Despite this result, the change in the concentration of $\mathrm{Hb}$ compared to the control group only occurred in the sixth and last week of the study. Other studies that evaluated the effects of a mixture of fibre found that the Fe balance was significantly lower for rats that were fed the fibre blend ${ }^{(48,49)}$.

It can be speculated, considering the positive effects of the fructans (inulin and oligofructose) on mineral absorption, that the levels of $5 \%$ of inulin associated with $5 \%$ of oligofructose (synergy1) are not sufficient to generate the same effects on the absorption of $\mathrm{Fe}$ as $10 \%$ of these prebiotics offered separately. Thus, the magnitude of the effect on the absorption of trace elements is affected by the type and dose of fructan ${ }^{(50)}$. Wolf et al $^{(51)}$ studied the effects of oligofructose (1, 3 and $\left.5 \%\right)$ on the apparent absorption and balance of various minerals, including $\mathrm{Fe}, \mathrm{Mg}, \mathrm{Zn}, \mathrm{Ca}$ and $\mathrm{P}$, and found that only the absorption of $\mathrm{Mg}$, in the group that received $5 \%$ of oligofructose in rations, was significantly higher than in the control group. A study comparing an intake of 5 and $10 \%$ of fructo-oligosaccharides with different chain sizes found that the highest concentration of fructo-oligosaccharides benefited the absorption of $\mathrm{Ca}$ and $\mathrm{Mg}$, but the size of the chain did not generate significant differences ${ }^{(52)}$.

It can be speculated that the higher stimulus to the absorption of Ca generated by synergyl, as shown in some studies, could inhibit the absorption of Fe, since the studies clearly showed an antagonistic relationship between $\mathrm{Ca}$ and dietary Fe absorption ${ }^{(53)}$.

Diets rich in dietary fibres could potentially reduce energy intake; so there is still no recommendation regarding the consumption of fibre in the first year of life, probably because of concerns that fibre may have negative effects on growth. This hypothesis is suggested because children have a lower gastric capacity and the energy density of foods rich in dietary fibre is low and these foods are capable of delaying gastric emptying, thus prolonging satiety ${ }^{(28)}$. However, in this study, there was no decrease in food intake or body growth.

The weight of the fresh and dried faeces and the faecal humidity showed that the HP inulin and synergy 1 prebiotics cause effects similar to those of soluble fibres ${ }^{(54)}$. These fibres are probably generated by the content of faecal water that is increased, and by the presence of bacteria, since these fibres are fully fermented and this fermentation extends to the most distal parts of the intestine, unlike with oligofructose.

In conclusion, this experimental study conducted with anaemic rats in the growth phase showed the benefit of HP inulin and oligofructose prebiotics on the regeneration of haemoglobinic mass. Synergy1 did not generate results to the same extent. The body growth and food intake were not prejudiced by the consumption of any of the studied prebiotics. It is important to emphasise that new studies evaluating the effect of synergy1 on intestinal absorption of Fe are needed, as well as studies in human infants evaluating the safety of foods that are rich in dietary fibre.

\section{Acknowledgements}

The present research was supported by 'Coordination of Improvement of Higher Education' - CAPES and the 'São Paulo Research Foundation' - FAPESP, Brazil. The authors' contributions were as follows: K. d. C. F., M. B. d. M. and O. M. S. A. were instrumental in the conception and design of the study. K. d. C. F. and M. B. d. M. were responsible for the generation of the study. K. d. C. F. and M. B. d. M. performed the assembly, analysis and interpretation of the data (statistical analysis). K. d. C. F., M. B. d. M. and O. M. S. A. contributed to the revision of the manuscript. None of the authors had any personal or financial interest in any organisation sponsoring this research or any conflict of interest related to their participation in this study.

\section{References}

1. Van Loo J, Cummings J, Delzenne N, et al. (1999) Functional food properties of non-digestible oligosaccharides: a consensus report from the ENDO project (DGXII AIRII-CT941095). Br J Nutr 81, 121-132.

2. Kolida S, Tuohy K \& Gibson GR (2002) Prebiotic effects of inulin and oligofructose. Br J Nutr 87, Suppl. 2, S193-S197.

3. Marteau P \& Boutron-Ruault MC (2002) Nutritional advantages of probiotics and prebiotics. Br J Nutr 87, Suppl. 2, S153-S157.

4. Coudray C, Tressol JC, Gueux E, et al. (2003) Effects of inulin-type fructans of different chain length and type of branching on intestinal absorption and balance of calcium and magnesium in rats. Eur J Nutr 42, 91-98.

5. Holloway L, Moynihan S, Abrams SA, et al. (2007) Effects of oligofructose-enriched inulin on intestinal absorption of calcium and magnesium and bone turnover markers in postmenopausal women. Br J Nutr 97, 365-372.

6. van den Heuvel EGHM, Muys T, Dokkum WV, et al. (1999) Oligofructose stimulates calcium absorption in adolescents. Am J Clin Nutr 69, 544-548.

7. Ohta A, Sakai K, Takasaki M, et al. (1999) Dietary heme iron does not prevent postgastrectomy anemia but fructooligosaccharides improve bioavailability of heme iron in rats. Int J Vitam Nutr Res 69, 348-355.

8. van den Heuvel EGHM, Schaafsma G \& Muys T (1998) Nondigestible oligosaccharides do not interfere with calcium and nonheme-iron absorption in young, healthy men. Am J Clin Nutr 67, 445-451.

9. Younes H, Coudray C, Bellanger J, et al. (2001) Effects of two fermentable carbohydrates (inulin and resistant starch) and their combination on calcium and magnesium balance in rats. Br J Nutr 86, 479-485.

10. Lopez HW, Coudray C, Levrat-Verny MA, et al. (2000) Fructooligosaccharides enhance mineral apparent absorption and counteract the deleterious effects of phytic acid on mineral homeostasis in rats. J Nutr Biochem 11, 500-508.

11. Freitas KC, Amancio OMS, Novo NF, et al. (2006) Partially hydrolyzed guar gum increases intestinal absorption of 
iron in growing rats with iron deficiency anaemia. Clin Nutr 25, 851-858.

12. Medeiros LCS, Morais MB, Tahan S, et al. (2007) Clinical characteristics of pediatric patients with chronic constipation according to age group. Arq Gastroenterol 44, 340-344.

13. Morais MB, Vítolo MR, Aguirre ANC, et al. (1999) Measurement of low dietary fiber intake as a risk factor for chronic constipation in children. J Pediatric Gastroenterol Nutr 29, $132-135$.

14. Davidsson L, Galan P, Cherouvrier F, et al. (1997) Biovailability in infants of iron from infant cereals: effect of dephytinization. Am J Clin Nutr 65, 916-920.

15. Aggett PJ, Agostoni C, Axelsson I, et al. (2002) Iron metabolism and requeriments in early childhood: do we know enough?: a commentary by the ESPGHAN Committee on Nutrition. J Pediatr Gastroenterol Nutr 34, 337-345.

16. Lozoff B, Jimenez E, Hagen J, et al. (2000) Poorer behavioral and developmental outcome more than 10 years after treatment for iron deficiency in infancy. Pediatrics 105, E51.

17. Pitarresi G, Tripodo G, Cavallaro G, et al. (2007) Inulin-iron complexes: a potential treatment of iron deficiency anemia. Eur J Pharm Biopharm 68, 267-276.

18. Yasuda K, Roneker KR, Miller DD, et al. (2006) Supplemental dietary inulin affects the biovailability of iron in corn and soybean meal to young pigs. J Nutr 136, 3033-3038.

19. Williams CL (1995) Importance of dietary fiber in childhood. J Am Diet Assoc 95, 1140-1146.

20. Trumbo P, Schlicker S, Yates AA, et al. (2002) Dietary reference intakes for energy, carbohydrate, fiber, fat, fatty acids, cholesterol, protein and amino acids. J Am Diet Assoc 102, $1621-1630$

21. Reeves PG, Nielsen FH \& Fahey GC (1993) AIN-93 purified diets for laboratory rodents: final report $f$ the American Institute of Nutrition ad boc writing committee on the reformulation of the AIN-76A rodent diet. J Nutr 123, 1939-1951.

22. Borel MJ, Smith SH, Brigham DE, et al. (1991) The impact of varying degrees of iron nutriture on several functional consequences of iron deficiency in rats. J Nutr 121, 729-736.

23. Marks GE, Moore CE, Kanabrocki EL, et al. (1971) Determination of trace elements in human tissue. I, Cd, Fe, $\mathrm{Zn}, \mathrm{Mg}$ and Ca. Appl Spectrosc 26, 523-527.

24. Jacobs LR \& White FA (1983) Modulation of mucosal cell proliferation in the intestine of rats fed a wheat bran diet. Am J Clin Nutr 37, 945-953.

25. Dirks P \& Freeman HJ (1987) Effects of differing purified cellulose, pectin and hemicellulose fiber diets on mucosal morphology in the rat small and large intestine. Clin Invest Med 10, 32-38.

26. Lopez HW, Levrat-Verny M, Coudray C, et al. (2001) Class 2 resistant starches lower plasma and liver lipids and improve mineral retention in rats. J Nutr 131, 1283-1289.

27. Wintrobe M, Mollin D, Herbert V, et al. (1968) Anemias nutricionales. Org Mund Salud Ser Inf Técn 405, 5-39.

28. Sierra Salinas C, Martínez Costa C, Dalmau Serra J, et al (2000) Revisión del papel de la fibra em nutrición infantile (Review of the role of fiber in child nutrition). Pediátrika 20, 129-137.

29. Dagnelie PC, van Staveren V, Verschuren SA, et al. (1989) Nutritional status of infants aged 4 to 18 months on macrobiotic diets and matched omnivorous control infants: a population- based mixed-longitudinal study. I. Weaning pattern, energy and nutrient intake. Eur J Clin Nutr 43, 311-323.

30. Kanauchi O, Araki Y, Andoh A, et al. (2000) Effect of germinated barley foodstuff administration on mineral utilization in rodents. J Gastroenterol 35, 188-194.
31. Ohta A, Ohtsuki M, Baba S, et al. (1995) Effects of fructooligosaccharides on the absorption of iron, calcium and magnesium in iron-deficient anemic rats. J Nutr Sci Vitaminol 41, 281-291.

32. Delzenne N, Aertssens J, Verplaetse H, et al. (1995) Effect of fermentable fructo-oligosaccharides on mineral, nitrogen and energy digestive balance in the rat. Life Sci $\mathbf{5 7}$, 1579-1587.

33. Ohta A, Ohtsuki M, Uehara M, et al. (1998) Dietary fructooligosaccharides prevent postgastrectomy anemia and osteopenia in rats. $J$ Nutr 128, 485-490.

34. Sakai K, Ohta A, Shiga K, et al. (2000) The cecum and dietary short-chain fructooligosaccharides are involved in preventing postgastrectomy anemia in rats. J Nutr 130, 1608-1612.

35. Weber TK, Freitas KC, Amancio OMS, et al. (2010) Effect of dietary fibre mixture on growth and intestinal iron in rats recovering from iron-deficiency anaemia. Br J Nutr $\mathbf{1 0 4}$ 1471-1476.

36. Catani M, Amancio OMS, Fagundes-Neto U, et al. (2003) Dietary cellulose has no effect on the regeneration of hemoglobin in growing rats with iron deficiency anemia. Braz Med Biol Res 36, 693-697.

37. Blachier F, Vaugelade P, Robert V, et al. (2007) Comparative capacities of the pig colon and duodenum for luminal iron absorption. Can J Physiol Pharmacol 85, 185-192.

38. Johnston KL, Johnson DM, Marks J, et al. (2006) Non-haem iron transport in the rat proximal colon. Eur J Clin Invest 36, 35-40

39. Tako E, Glahn RP, Welch RM, et al. (2007) Dietary inulin affects the expression of intestinal enterocyte iron transporters, receptors and storage protein and alters the microbiota in the pig intestine. Br J Nutr 99, 472-480.

40. Pérez-Conesa D, López G \& Ros G (2007) Effects of probiotic, prebiotic and symbiotic follow-up infant formulas on large intestine morphology and bone mineralisation in rats. J Sci Food Agric 87, 1059-1068.

41. Frankel WL, Zhang W, Singh A, et al. (1994) Mediation of the trophic effects of short-chain fatty acids on the rat jejunum and colon. Gastroenterology 106, 375-380.

42. Bouglé D, Vaghefi-Vaezzadeh N, Roland N, et al. (2002) Influence of short-chain fatty acids on iron absorption by proximal colon. Scand J Gastroenterol 37, 1008-1011.

43. Balamurugan R, Regina Mary R, Chittaranjan C, et al. (2010) Low levels of faecal lactobacilli in women with irondeficiency anaemia in south India. Br J Nutr 104, 931-944.

44. Patterson JK, Yasuda K, Welch RM, et al. (2010) Supplemental dietary inulin of variable chain lengths alters intestinal bacterial populations in young pigs. $J$ Nutr 140, 2158-2161.

45. Tako E, Glahn RP \& Welch RM (2008) Dietary inulin affects the expression of intestinal enterocyte iron transporters, receptors and storage protein and alters the microbiota in the pig intestine. BrJ Nutr 99, 472-480.

46. Morais MB, Feste A, Miller RG, et al. (1996) Effect of resistant and digestible starch on intestinal absorption of calcium, iron, and zinc in infant pigs. Pediatr Res 39, 872-876.

47. Fukunaga T, Sasaki M, Araki Y, et al. (2003) Effects of the soluble fibre pectin on intestinal cell proliferation, fecal short chain fatty acid production and microbial population. Digestion 67, 42-49.

48. Galibois I, Desrosiers T, Guévin N, et al. (1994) Effects of dietary fibre mixtures on glucose and lipid metabolism and on mineral absorption in the rat. Ann Nutr Metab 38, 203-211.

49. Wang Y, Funk MA, Garleb KA, et al. (1994) The effect of fiber source in enteral products on fecal weight, mineral balance, 
and growth rate in rats. JPEN J Parenter Enteral Nutr 18 $340-345$.

50. Scholz-Aherns KE \& Schrezenmeir J (2007) Inulin and oligofructose and mineral metabolism: the evidence from animal trials. J Nutr 137, 2513-2523.

51. Wolf BW, Firkins JL \& Zhang X (1998) Varying dietary concentrations of fructooligosaccharides affect apparent absorption and balance of minerals in growing rats. Nutr Res $\mathbf{1 0}$, 1791-1806.
52. Ohta A, Ohtsuki M, Baba S, et al. (1998) Comparison of the nutritional effects of fructo-oligosaccharides of different sugar chain length in rats. Nutr Res 1, 109-120.

53. Hallberg L, Brune M, Erlandsson M, et al. (1991) Calcium: effect of different amounts on nonheme- and heme-iron absorption in humans. Am J Clin Nutr 53, 112-119.

54. Nyman M (2002) Fermentation and bulking capacity of indigestible carbohydrates: the case of inulin and oligofructose. Br J Nutr 87, Suppl. 2, S163-S168. 